\title{
Density Functional Theory Study of Structural and Electronic Properties of Group V Transition Metal Carbides
}

\author{
JAMESON MAIBAM $^{1}$, KH. KABITA ${ }^{1}$, B. INDRAJIT SHARMA ${ }^{1 *}$, \\ DINESHCHANDRA HAOBIJAM ${ }^{2}$, R.K. BROJEN ${ }^{2}$ AND R. K. THAPA $^{3}$ \\ ${ }^{1}$ Department of Physics, Assam University, Silchar-788011, Assam, India. \\ ${ }^{2}$ School of Computational and Integrative Sciences, JNU, New Delhi 110067, India \\ ${ }^{3}$ Department of Physics, Mizoram University, Tanhril, Aizawl-796 009, India \\ *Email: indraofficial@ rediffmail.com
}

Received: May 05, 2015 IRevised: August 12, 2015 IAccepted: October 17, 2016

Published online: February 08, 2016, The Author(s) 2016. This article is published with open access at www.chitkara.edu.in/publications

\begin{abstract}
The structural and electronic properties of group $\mathrm{V}$ transition metal carbides: $\mathrm{VC}, \mathrm{NbC}$ and $\mathrm{TaC}$ are studied using density functional theory with generalized gradient approximation for the exchange and correlation potential. Lattice constants, bulk moduli, elastic constants, energy band diagrams, density of states of the carbides are reported and their trends are discussed. From the band diagrams, the band separation, zone-centre $\mathrm{d}$ band splitting, non metal $\mathrm{p}$ and $\mathrm{s}$ band splitting, width of $2 \mathrm{p}$ band, and $4 \mathrm{~d}$ band explains the insight of electronic structure of these compounds.
\end{abstract}

Keywords: Density functional theory; energy band diagram; elastic constants

\section{INTRODUCTION}

The transition-metal carbides belong to the family of refractory (hard metals). The refractory group can be formed by combining boron, carbon, or nitrogen with group-IV, V \& VI transition series elements [13]. They are well known for possessing a number of extreme properties that are of scientifically interest and technologically important. Several of the compounds have high super-conducting transition temperature $\mathrm{T}_{\mathrm{c}}$ showing a strong electron phonon interaction [16]. In the view of these properties, a large number of theoretical investigations have been carried out in the last few decades $[1,2,7,8,12,20,21]$. The physical properties like extreme hardness are due to the presence of their unusual combination of bonding

Journal of Nuclear

Physics, Material Sciences, Radiation and Applications Vol-3, No-2

Feburary 2016 pp. 157-164 
Maibam, J. Kabita, Kh

Sharma, I Haobijam, D Brojen, RK Thapa, RK

mechanisms. The other properties like high melting points and electrical conductivity are of equal interest. These compounds often crystallize in rock salt structure [13]. The aim of this paper is to present the results of a theoretical investigations on the electronic structure and elastic properties of $\mathrm{VC}, \mathrm{NbC}$ and $\mathrm{TaC}$. The present work is organized as follows. The theory and method of electronic structure calculation are discussed in section 2 . We present our results and discussion in section 3 . In section 4 , we draw some conclusions based on our results.

\section{METHODS OF CALCULATION}

The quantum many body problem with Born-Oppenheimer approximation is much simpler, but still too far difficult to solve. Several methods exist to reduce this many particle Hamiltonian to an approximate one but in tractable form. One of the most powerful methods to reduce in such approximate form is Density Functional Theory (DFT) $[19,22,25]$. Within this formalism, the total energy can be expressed as a functional of density of electron system, $\rho$ and can be written by the following functional,

$$
\mathrm{E}[\rho]=\mathrm{T}_{\mathrm{o}}[\rho]+\mathrm{V}_{\mathrm{H}}[\rho]+\mathrm{V}_{\mathrm{xc}}[\rho]+\mathrm{V}_{\mathrm{ext}}[\rho]
$$

where, $T_{0}[\rho]$ is the kinetic energy of a non-interacting electron system, $V_{H}[\rho]$ and $\mathrm{V}_{\mathrm{xc}}[\rho]$ are the Hartree and exchange-correlation contributions to the energy and $V_{e x t}[\rho]$ is the energy due to the external potential of the system. Thus the corresponding Hamiltonian called the Kohn-Sham Hamiltonian is

$$
\begin{aligned}
\hat{\mathrm{H}}_{\mathrm{KS}} & =\widehat{\mathrm{T}}_{\mathrm{o}}+\widehat{\mathrm{V}}_{\mathrm{H}}+\widehat{\mathrm{V}}_{\mathrm{XC}}+\widehat{\mathrm{V}}_{\mathrm{ext}} \\
& =-\frac{\hbar^{2}}{2 \mathrm{~m}_{\mathrm{e}}} \vec{\nabla}_{\mathrm{i}}^{2}+\frac{\mathrm{e}^{2}}{4 \pi \varepsilon_{\mathrm{o}}} \int \frac{\rho\left(\overrightarrow{\mathrm{r}}^{\prime}\right)}{\left|\overrightarrow{\mathrm{r}}-\overrightarrow{\mathrm{r}}^{\prime}\right|} \mathrm{d}^{\prime}{ }^{\prime}+\mathrm{V}_{\mathrm{XC}}+\mathrm{V}_{\mathrm{ext}}
\end{aligned}
$$

The exact density of $\mathrm{N}$ electron system can be expressed in ground state by, $\rho(\overrightarrow{\mathrm{r}})=\sum_{\mathrm{i}=1}^{\mathrm{N}} \phi_{\mathrm{i}}(\overrightarrow{\mathrm{r}})^{*} \phi_{\mathrm{i}}(\overrightarrow{\mathrm{r}})$ where the single particle wave functions $\Phi_{i}(\mathrm{r})$ are the $\mathrm{N}$ lowest energy solutions of the Kohn Sham equation: $\hat{\mathrm{H}}_{\mathrm{ks}} \Phi_{\mathrm{i}}=\epsilon_{\mathrm{i}} \Phi_{\mathrm{i}}$ of the N electron system. These equations can be solved self consistently in an iterative process. Thus the energy band is calculated using Full Potential-Linearized Augmented Plane wave (FP-LAPW) method within the Density Functional formalism in its local density approximation [17]. In this method, the unit cell is divided into nonoverlapping atomic spheres (muffin tin spheres) and an interstitial region. Within 
the muffin tin sphere, one constructs the basis set as linear combination of radial functions multiplied by spherical harmonics. Whereas, a plane wave expansion is used as basis set in the interstitial region. The exchange and correlation potential is incorporated by using generalized gradient approximation (GGA) parameterized by Perdew et al [11]. For every case the wave functions inside the MT spheres which are expanded into spherical harmonics are upto $1=9$ and the RKmax $=10$. The number of $\mathrm{k}$ points used for the integration procedure is 5000 which reduces to 165 irreducible $\mathrm{k}$ points inside the Brillion zone. In this work, the states treated as bands are: for $\mathrm{V}(3 \mathrm{~s}, 3 \mathrm{p}, 3 \mathrm{~d}, 4 \mathrm{~s}) ; \mathrm{Nb}(4 \mathrm{~s}, 4 \mathrm{p}, 4 \mathrm{~d}, 5 \mathrm{~s}) ; \mathrm{Ta}(5 \mathrm{~s}, 5 \mathrm{p}, 5 \mathrm{~d}, 6 \mathrm{~s}) ; \mathrm{C}(2 \mathrm{~s}, 2 \mathrm{p})$ and $\mathrm{N}(2 \mathrm{~s}, 2 \mathrm{p})$. The calculations are performed at the equilibrium lattice constants which are determined from a plot of total energy against the unit cell volume by fitting to the Murnaghan equation of state [10]. The overall simulation work is carried out using wien $2 \mathrm{k}$ code [18].

\section{RESULTS AND DISCUSSION}

\subsection{Structural and Elastic Properties}

A series of different lattice constants are used to calculate the total energy and the corresponding unit cell volume to optimize the rock salt structure of the group $\mathrm{V}$ transition metal carbides ( $\mathrm{VC}, \mathrm{NbC}, \mathrm{TC})$. Figure $1(\mathrm{a}, \mathrm{b}, \mathrm{c})$ shows the total energy curve as a function of unit cell volume and fitted with Murnaghan equation of state [10]. The obtained equilibrium lattice parameter $\left(\mathrm{a}_{0}\right)$, bulk modulus $\left(\mathrm{B}_{0}\right)$, and pressure derivative of the bulk modulus (B') are presented in table 1. These values are compared with previous theoretical and experimental results as calculated by other groups $[3,4,6,9,13,24]$. It shows that our results are reasonably in agreement with previous reported data. Hence this optimized structure is used for further study of elastic properties of the optimized lattice constant, the elastic constants $\mathrm{C}_{11}, \mathrm{C}_{12}$ and $\mathrm{C}_{44}$ are calculated using the stress-strain method [3, 6, 9].

Table 1: Lattice constant $\left(\mathrm{a}_{0}\right)$, bulk modulus (B), pressure derivatives (B') and elastic constants $\left(\mathrm{C}_{11}, \mathrm{C}_{12}, \mathrm{C}_{44}\right)$.

\begin{tabular}{llll}
\hline & VC & NbC & TaC \\
\hline $\mathrm{a}_{0}\left(\mathrm{~A}^{0}\right)$ & $4.165(4.170)^{\mathrm{a}}$ & $4.683(4.470)^{\mathrm{c}}$ & $4.484(4.456)^{\mathrm{d}}$ \\
$\mathrm{B}(\mathrm{Mbar})$ & $314.860(4.142)^{\mathrm{b}}$ & $300.031(302.000)^{\mathrm{c}}$ & $325.56(3.420)^{\mathrm{e}}$ \\
$\mathrm{B}^{\prime}$ & 3.388 & 3.894 & 8.244 \\
$\mathrm{C}_{11}(\mathrm{GPa})$ & 5.056 & 6.022 & 8.129 \\
$\mathrm{C}_{12}(\mathrm{GPa})$ & 1.288 & 0.945 & 0.819 \\
$\mathrm{C}_{44}(\mathrm{GPa})$ & 1.842 & 1.743 & 1.769 \\
\hline
\end{tabular}

${ }^{\mathrm{a}} \operatorname{Ref} .[25],{ }^{\mathrm{b}} \operatorname{Ref} .[17],{ }^{\mathrm{c}} \operatorname{Ref} .[13],{ }^{\mathrm{d}} \operatorname{Ref} .[11,10],{ }^{\mathrm{c}} \operatorname{Ref} .[18]$; 
Maibam, J.

Kabita, Kh

Sharma, I

Haobijam, D

Brojen, RK

Thapa, RK
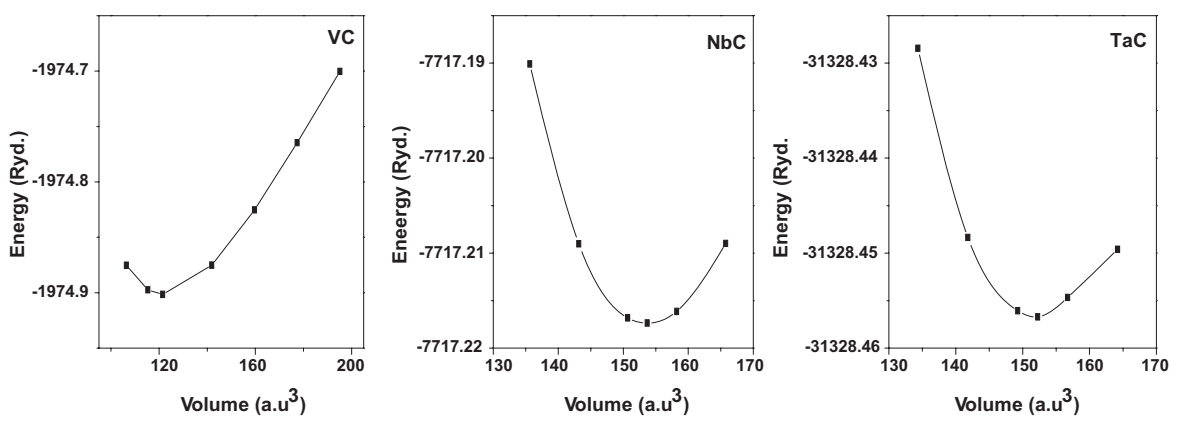

Figure 1: Energy verses Volume for (a)VC, (b) NbC, (c) TaC.

The elastic constants $\mathrm{C}_{11}, \mathrm{C}_{12}$ and $\mathrm{C}_{44}$ are listed in table 1 and they satisfy the mechanical stability conditions for a cubic crystal system given by: $\left(\mathrm{C}_{11}+2 \mathrm{C}_{12}\right)>0 ; \mathrm{C}_{11} \mathrm{C}_{12}>0 ; \mathrm{C}_{44}>0$. Thus the group $\mathrm{V}$ transition metal carbides in rock salt structure is mechanically stable.

\subsection{Electronic Structure}

The energy band diagram of $\mathrm{VC}, \mathrm{NbC}$ and $\mathrm{TaC}$ are shown in figure $2(\mathrm{a}, \mathrm{b}, \mathrm{c})$ respectively. In the energy band diagrams, one can see the lowest valence and conduction band. Also there is crossover of valence band and conduction band towards the Fermi level. It indicates that these carbides show metallic nature. Figure 3(a, b), Figure 4(a, b) and Figure $5(\mathrm{a}, \mathrm{b})$ show the partial density of states of $\mathrm{V}, \mathrm{Nb}, \mathrm{Tc}$ and $\mathrm{C}$ atom in $\mathrm{VC}, \mathrm{NbC}, \mathrm{TaC}$ respectively. To understand the contribution of orbital states in the band diagrams, we need to analyze thoroughly the partial density of states of the atoms in the system. The partial DOS, as shown in figure 3 , figure 4 and figure 5 clearly shows that the valence
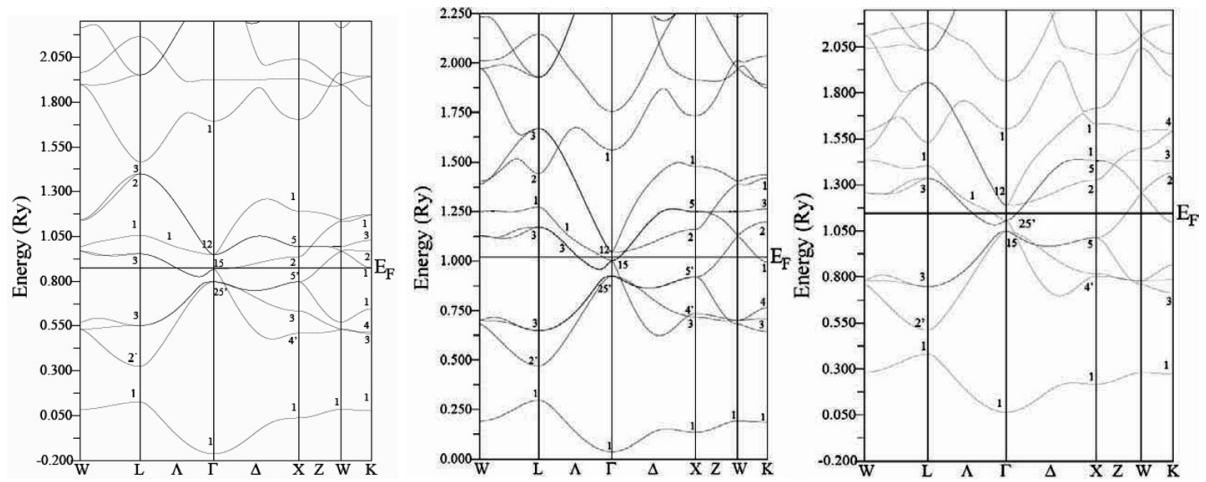

Figure 2: Band diagram of (a) VC, (b) NbC , (c) TaC. 

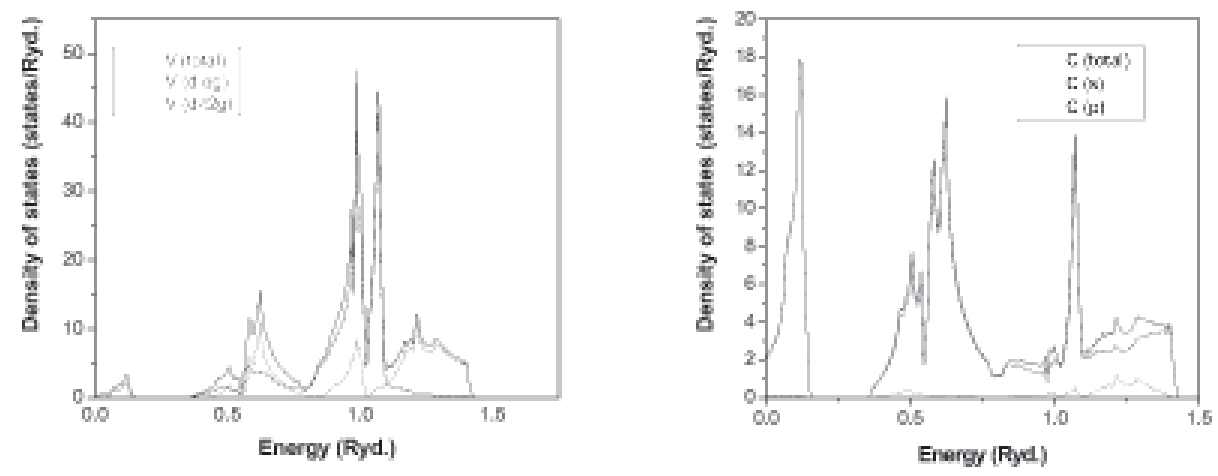

Density Functional Theory Study of Structural and Electronic

Properties of Group V Transition Metal Carbides

Figure 3: Partial DOS of (a) V in VC, (b) $\mathrm{C}$ in VC.
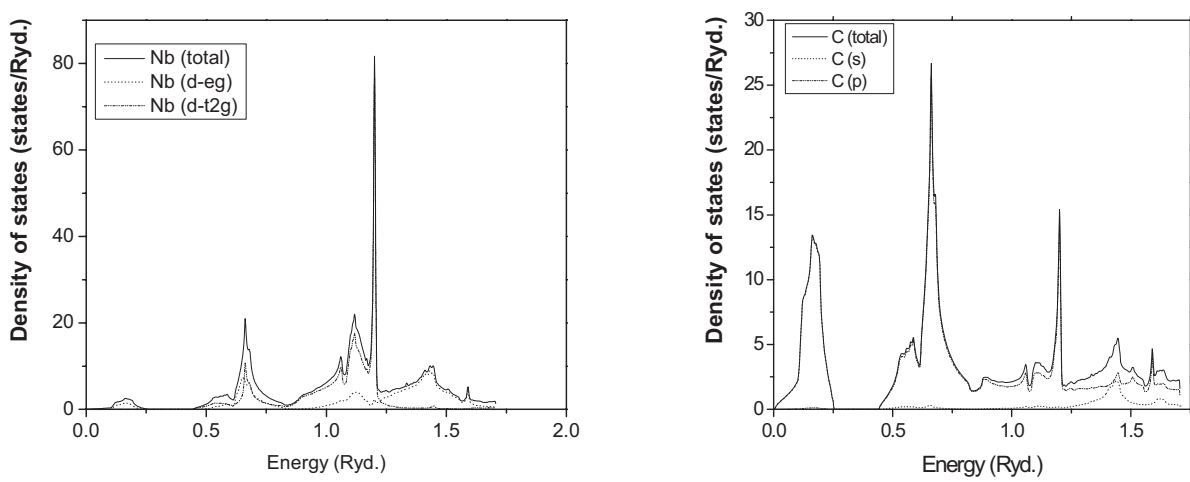

Figure 4: Partial DOS of (a) $\mathrm{Nb}$ in $\mathrm{NbC}$, (b) $\mathrm{C}$ in $\mathrm{NbC}$.
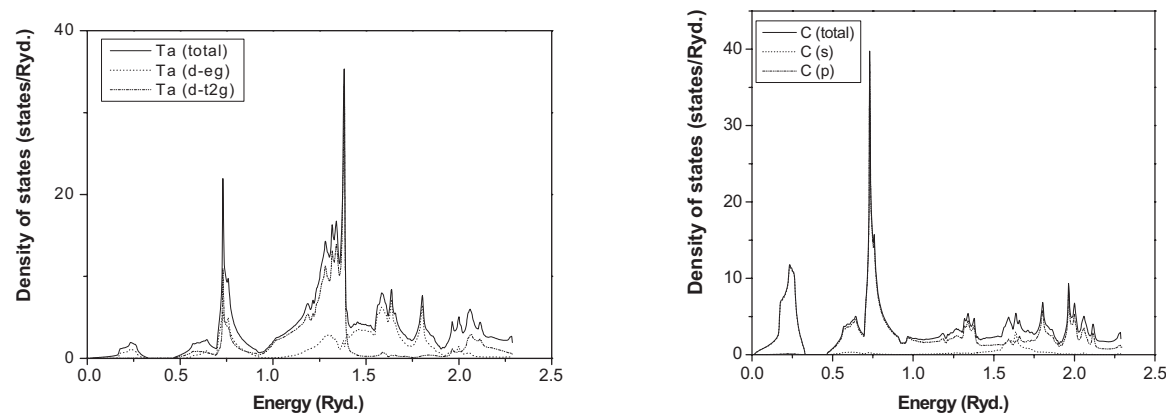

Figure 5 : Partial DOS of (a) $\mathrm{Ta}$ in $\mathrm{TaC}$, (b) $\mathrm{C}$ in $\mathrm{TaC}$.

band in energy band diagrams are mainly contributed by the nonmetal $2 \mathrm{~s}$ orbital state of $\mathrm{C}$ atom. The valence bands are mainly due to nonmetal $\mathrm{p}$ state and metal $\mathrm{p}$ state. 
Maibam, J. Kabita, Kh

Sharma, I

Haobijam, D

Brojen, RK

Thapa, RK
Table 2: Band separations (Ry) in band diagram obtained from GGA, APW, LDA calculations.

\begin{tabular}{lllllllll}
\hline & VC & \multicolumn{3}{c}{$\mathrm{NbC}$} & & \multicolumn{3}{c}{$\mathrm{TaC}$} \\
& $\mathbf{G G A}^{\mathbf{a}}$ & $\mathbf{A P W}^{\mathbf{b}}$ & $\mathbf{G G A}^{\mathbf{a}}$ & $\mathbf{G G A}^{\mathbf{c}}$ & $\mathbf{A P W}^{\mathbf{c}}$ & $\mathbf{L D A}^{\mathbf{b}}$ & $\mathbf{G G A}^{\mathbf{a}}$ & $\mathbf{L D A}^{\mathbf{d}}$ \\
\hline $\mathrm{E}_{\mathrm{F}}$ & 0.876 & ---- & 1.020 & 1.055 & 0.770 & 1.085 & 1.143 & 0.091 \\
$\mathrm{E}_{\mathrm{gL}}$ & 0.199 & 0.210 & 0.174 & 0.173 & 0.250 & 0.138 & 0.129 & 0.081 \\
$\Delta \mathrm{E}_{\mathrm{d}}$ & 0.152 & 0.070 & 0.110 & 0.119 & 0.133 & 0.128 & 0.082 & 0.084 \\
$\mathrm{E}_{\mathrm{d}}-\mathrm{E}_{\mathrm{p}}$ & 0.001 & 0.100 & 0.030 & 0.031 & 0.150 & 0.032 & 0.093 & 0.356 \\
$\mathrm{E}_{\mathrm{p}}-\mathrm{E}_{\mathrm{s}}$ & 1.031 & 0.940 & 0.965 & 0.965 & 0.870 & 0.969 & 0.981 & ------- \\
\hline
\end{tabular}

${ }^{a}$ Ref. Our result, ${ }^{\mathrm{b}}$ Ref. [5], ${ }^{\mathrm{c}}$ Ref. [14 ,23], ${ }^{\mathrm{d}}$ Ref. [15]

It is also notice that there is a small contribution of metal d states. One can observe that the $2 \mathrm{~s}$ band has maximum dispersion between $\Gamma$ and $\mathrm{L}$. Above this band, there lies the $2 \mathrm{p}$ non-metal and $4 \mathrm{~d}$ metal states. These bands overlap and mixed in $\Delta$. The $4 \mathrm{~d}$ metal state is further decomposed to $\mathrm{t}_{2 \mathrm{~g}}$ and originating from $\Gamma_{25}$, and $\mathrm{e}_{\mathrm{g}}$ originating from $\Gamma_{12}$. So the width of the $\mathrm{d}$ band is given by $\Delta \mathrm{E}_{\mathrm{d}}=\mathrm{E}\left(\Gamma_{12}\right)-\mathrm{E}\left(\Gamma_{25}\right)$. In our calculation, the energy gap $\mathrm{E}_{\mathrm{gL}}$ is the band separation of lowest band and valence band at $\mathrm{L}$ point. The zone centre $\mathrm{d}$ band splitting $\Delta \mathrm{E}_{\mathrm{d}}$, the metal-d \& non-metal-p splitting, $\mathrm{E}_{\mathrm{d}}-\mathrm{E}_{\mathrm{p}}=\left[2 / 5 \mathrm{E}\left(\Gamma_{12}\right)+3 / 5\right.$ $\left.\mathrm{E}\left(\Gamma_{25}\right)\right]-\mathrm{E}\left(\Gamma_{15}\right)$, nonmetal p \& metal s splitting, $\mathrm{E}_{\mathrm{p}}-\mathrm{E}_{\mathrm{s}}=\mathrm{E}\left(\Gamma_{15}\right)-\mathrm{E}\left(\Gamma_{1}\right)$ are given in table 2. Our band structure calculation parameters are in good agreement with the reported in the literatures $[2,5,14,15,23]$.

\section{CONCLUSIONS}

This work reports the results of a systematic study on the electronic and structural properties of group $\mathrm{V}$ transition metal carbides. The optimized lattice constant of $\mathrm{VC}, \mathrm{NbC}$ and $\mathrm{TaC}$ are found as $4.165 \mathrm{~A}^{\circ}, 4.683 \mathrm{~A}^{\circ}$ and $4.4834 \mathrm{~A}^{\circ}$ which are in good agreement with the reported experimental and calculated values. The elastic constants $\left(\mathrm{C}_{11}, \mathrm{C}_{12}, \mathrm{C}_{44}\right)$ satisfy the mechanical stability conditions: $\left(\mathrm{C}_{11}+2 \mathrm{C}_{12}\right)>0 ; \mathrm{C}_{11} \mathrm{C}_{12}>0 ; \mathrm{C}_{44}>0$. Thus the group $\mathrm{V}$ transition metal carbides ( $\mathrm{VC}, \mathrm{NbC}, \mathrm{TaC}$ ) are found to be stable compound in rock salt structure. From a comparison of the band structures, one concludes the behavior is directly related to the hybridization of the metal-d and non metal-p valence states near $\mathrm{E}_{\mathrm{F}}$. The change in the overlapping and mixing between metal $\mathrm{d}$ ( $3 \mathrm{~d}$ for $\mathrm{V}, 4 \mathrm{~d}$ for $\mathrm{Nb}$ and $5 \mathrm{~d}$ for Ta) and non metal-2p bands are random. The value of band gap, zone-centre $\mathrm{d}$ band splitting, non metal 
$\mathrm{p}$ and $\mathrm{s}$ band splitting explains the insight of electronic structure of group $\mathrm{V}$ transition metal carbides.

\section{REFERENCES}

[1] A. Papaconstantopoulos, W. E. Pickett, and L. L. Boyer, Nature. 308 (1984) 494. http://dx.doi.org/10.1038/308494a0

[2] B. M. Kelein, D. A. Papaconstantopoulos and L. L. Boyer, Phys. Rev. B. 22 (1980) 1946. http://dx.doi.org/10.1103/PhysRevB.22.1946

[3] B. Mayer, H. Anton, E. Bott, M. Methfessel, J. Sticht, and P. C. Schmidt, Intermetallics. 11 (2003) 23.

http://dx.doi.org/10.1016/S0966-9795(02)00127-9

[4] B. R. Zhao, L. Chen and H. L. Luc, Phys. Rev. B . 29 (1984) 6198 http://dx.doi.org/10.1103/PhysRevB.29.6198

[5] D. A. Papaconstantopoulos, W.E. Pickett and L.L. Boyer, Phys. Rev. B. 31 (1985) 752. http://dx.doi.org/10.1103/PhysRevB.31.7093

[6] D. C. Wallace, Thermodynamics of crystals, Wiley New York, (1972).

[7] D. D. Koelling, Rep. Prog. Phys. 44 (1981) 139. http://dx.doi.org/10.1088/0034-4885/44/2/002

[8] D. H. Douglass, Superconductivity in d- and f- Band Metals, Plenum New York, (1976). http://dx.doi.org/10.1007/978-1-4615-8795-8

[9] F. Birch, J. Appl. Phys. 9 (1938) 279. http://dx.doi.org/10.1063/1.1710417

[10] F. D. Murnaghan, Proc. Natl. Acad. Sci. USA. 30 (1944) 244. http://dx.doi.org/10.1073/pnas.30.12.382

[11] J. P. Perdew and M. Ernzerhof, Phys. Rev. Lett. 77 (1996) 3865. http://dx.doi.org/10.1103/PhysRevLett.77.3865

[12] K. Schwarz, J. Phys. C. 10 (1977) 195. http://dx.doi.org/10.1088/0022-3719/10/2/007

[13] L.E. Toth, Transistion Metal Carbides and Nitrides, Academic New York, (1971).

[14] M. Gupta and A. J. Freeman, Phys. Rev. B. 14 (1976) 5205. http://dx.doi.org/10.1103/PhysRevB.14.5205

[15] M. Sahnoun, C. Daul, M. Driz, J. C. Parlebas and C. Demangeat, Comput. Mater. Sci. 33 (2005) 175. http://dx.doi.org/10.1016/j.commatsci.2004.12.010

[16] N. Pessall, R. E. Gold and H.A. Johnsen, J. Phys. Chem. Solids. 29 (1968) 19. http://dx.doi.org/10.1016/0022-3697(68)90251-5

[17] P. Blaha, K. Schwarz, P. Sorantin and S. B. Trickey, Comput. Phys.Commun. 59 (2) (1990) 399. http://dx.doi.org/10.1016/0010-4655(90)90187-6

[18] P. Blaha, K. Schwarz, G.K.H. Madsen, D. Kvasnicka and J. Luitz, WIEN2k An

[19] P. Hohenberg and W. Kohn, Phys.Rev. 136(3B) (1964) 864.

http://dx.doi.org/10.1103/PhysRev.136.B864
Density Functional Theory Study of Structural and Electronic Properties of Group V Transition Metal Carbides 
Maibam, J. Kabita, Kh Sharma, I Haobijam, D Brojen, RK Thapa, RK
[20] P. Rhodes, Physics of Transition metals, IOP London, (1981).

[21] P. Weinberger, R. Podloucky, C. P. Mallet and A. Neckel, J. Phys. C. 12 (1979) 801. http://dx.doi.org/10.1088/0022-3719/12/5/011

[22] S. Cottenier, Density Functional Theory and the family of (L)APW-methods: a step-

[23] T. Amriou, B. Bouhafs, H. Aourag, B. Khelifa, S. Bresson and C. Mathieu, Physica B. 325 (2003) 46. http://dx.doi.org/10.1016/S0921-4526(02)01429-1

[24] V.P.Zhukov, V. A. Gubanov, O. Jepsen, N. E. Christensen and O.K. Anderson, J. Phys. Chem. Solids. 49 (1988) 814. http://dx.doi.org/10.1016/0022-3697(88)90037-6

[25] W. Kohn and L. J. Sham, Phys. Rev. 140 (4A) (1965) 1133. http://dx.doi.org/10.1103/PhysRev.140.A1133 